\title{
Lase Sensing of Atmosphere
}

\author{
A. Padma Priya ${ }^{1}$, G. Madhu ${ }^{2}$ \\ ${ }^{1,2}$ Assistant Professor, ECE Department, CMR Institute of Technology, Hyderabad, India
}

\begin{abstract}
The Lidar Atmospheric Sensing Experiment (LASE) is the first fully-engineered, autonomous Differential Absorption Lidar (DIAL) System for the measurement of water vapor in the troposphere (aerosol and cloud measurements are included). Water vapor exists in the atmosphere only in small amounts, but it plays a big role in many important atmospheric processes. For example, water vapor is a fundamental part of the atmospheric energy budget, global water cycle, atmospheric chemistry, and transport processes of pollution. We present the use of Lidar Atmospheric Sensing Experiment (LASE) system to obtain comprehensive, remote water vapor observations for a better understanding of its many roles in the atmosphere.
\end{abstract}

Keywords: Lidar Atmospheric Sensing Experiment, Differential Absorption Lidar, Aerosol.

\section{Introduction}

Since the 1960s, scientists have used LIDARS (LIght Detection And Ranging) to study the atmosphere. A LIDAR is an instrument that uses short pulses of laser light to detect particles or gases in the atmosphere, like a radar bounces radio waves off rain drops in clouds. A telescope collects and measures reflected laser radiation, like a radar dish collects the radar signal, leading to a profile of the atmosphere's structure along the path of the laser beam. Researchers can then determine the location, distribution, and nature of atmospheric particles and molecular species using an advanced lidar method called the Differential Absorption Lidar (DIAL) technique. Differential Absorption Lidar (DIAL) is a technique that is uniquely suited for making precise water vapor measurements in the troposphere $[1,2,3]$. Water vapor measurements made with the LASE instrument using the DIAL technique have been validated with results showing an accuracy of better than $10 \%$ for water vapor profiles across the troposphere [4]. No other instrument can provide the spatial coverage and accuracy of LASE.

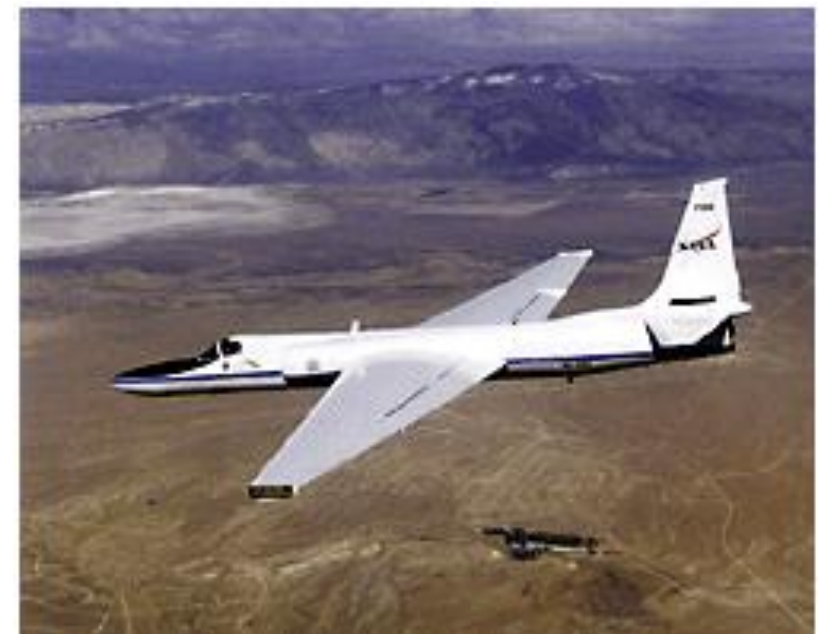

Figure 1: An ER - 2 uses LASE to take measurements of the atmosphere

Water vapor is the most radiative active gas in the troposphere, and the lack of understanding about its distribution provides one of the largest uncertainties in modeling climate change. LASE has demonstrated the necessary potential in providing high resolution water vapor measurements that can advance the studies of LASE on six different major atmospheric field investigations. During the first two field experiments, LASE operated as an autonomous (controlled by a pilot) lidar aboard an ER-2 (Earth Resource) aircraft as shown in fig-1.

\section{Differential Absorption Lidar (DIAL) System}

The ability of a Differential Absorption Lidar (DIAL) system is to measure vertical profiles of water vapor in the lower atmosphere. Tunable lasers are used that require real-time experimental control to locate and lock onto the atmospheric water vapor absorption line for the DIAL measurements. The Lidar Atmospheric Sensing Experiment (LASE) is the first step in a long-range effort to develop and demonstrate autonomous DIAL systems from airborne and spaceborne platforms.

A simplified version of the Differential Absorption Lidar (DIAL) concept is shown in the figure 2. With the DIAL technique, the gas concentration profile is determined by analyzing the lidar backscatter signals for laser wavelengths tuned "on" ( on) and "off" ( off) an absorption line of the gas of interest. The absorption regions are in the UV near $300 \mathrm{~nm}$ for ozone and in the IR near 727 or $815 \mathrm{~nm}$ for water vapor. In this technique, the wavelength separation between the on and off wavelengths is minimized to avoid differences in the atmospheric backscatter at the two wavelengths. The value of the average gas concentration NA (cm-3) in the range interval from R1 to R2 can be determined from the ratio of the lidar signals at the on and off wavelengths, where $\mathrm{s}_{\mathrm{A}}(\mathrm{on})-\mathrm{s}_{\mathrm{A}}$ (off) is the difference between the absorption cross-sections at the on and off wavelengths, and power received $\mathrm{Pr}$,on(Ri) and $\mathrm{Pr}$,off(Ri) are the signal powers received from range $\mathrm{Ri}$ at the on and off wavelengths, respectively.

The location of this range cell can be moved along the length of the lidar returns, providing the profile of the gas along the line-of-sight of the DIAL system. The gas mixing ratio profile can then be obtained by dividing the gas concentration profile by the atmospheric number density profile along the same direction. The aerosol and cloud distributions can be obtained at the same time from the lidar return at the off wavelength. 


\section{International Journal of Science and Research (IJSR)}

ISSN (Online): 2319-7064

Index Copernicus Value (2015): 78.96 $\mid$ Impact Factor (2015): 6.391

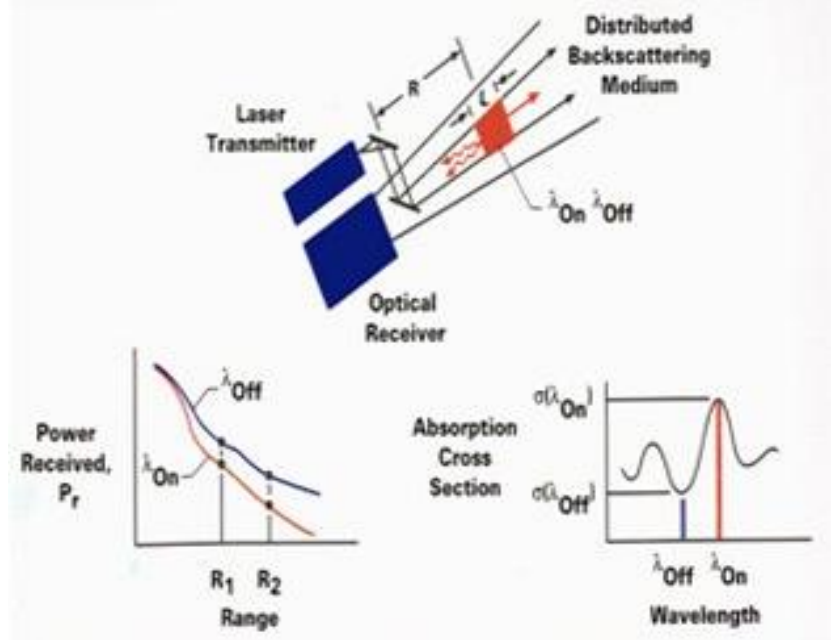

Figure 2: A simplified version of the Differential Absorption Lidar (DIAL)

To remotely measure ozone concentrations in the troposphere, the DIAL technique requires "on" to be in the Hartley-Huggins band near $289 \mathrm{~nm}$, and due to the nature of the ozone absorption, the nearest appropriate wavelength that can be used as the "off" is at the edge of the absorption band near $300 \mathrm{~nm}$. Since the ozone mixing ratio in the troposphere varies over a wide range from 10 to $150 \mathrm{pp}$ bv, "on" is often adjusted to optimize the DIAL measurement for each field experiment. For stratospheric DIAL measurements of ozone, "on" near $301 \mathrm{~nm}$ and "off" near $311 \mathrm{~nm}$ are used.

\section{Lidar Atmospheric Sensing Experiment}

LASE uses the DIAL technique to determine vertical profiles of water vapor in the lower atmosphere. It measures water vapor, clouds, and aerosols by comparing the absorption and scattering of different laser pulses on these atmospheric species. Laser beams are pointed out of the aircraft both upwards and downwards. Researchers operate LASE in the near infrared region of the electromagnetic spectrum and set one laser pulse to one wavelength, so water vapor will absorb the radiation, and another laser pulse to a slightly different wavelength to measure aerosols and clouds. LASE compares the two laser pulses as the atmosphere reflects them back to the telescope. Scientists use differences in the amount of laser light to determine the location and amount of water vapor, aerosols, and clouds in the atmosphere, essentially creating an atmospheric map of the area above and below the aircraft. LASE can measure water vapor distributions from the ground up to 20 kilometers. An example of simultaneous measurements of water vapor and aerosol distributions by LASE in the atmosphere is shown in fig. 2. These data were taken from the ER-2 aircraft as it flew back from near Bermuda to Wallops Island, Virginia, in July 1996.
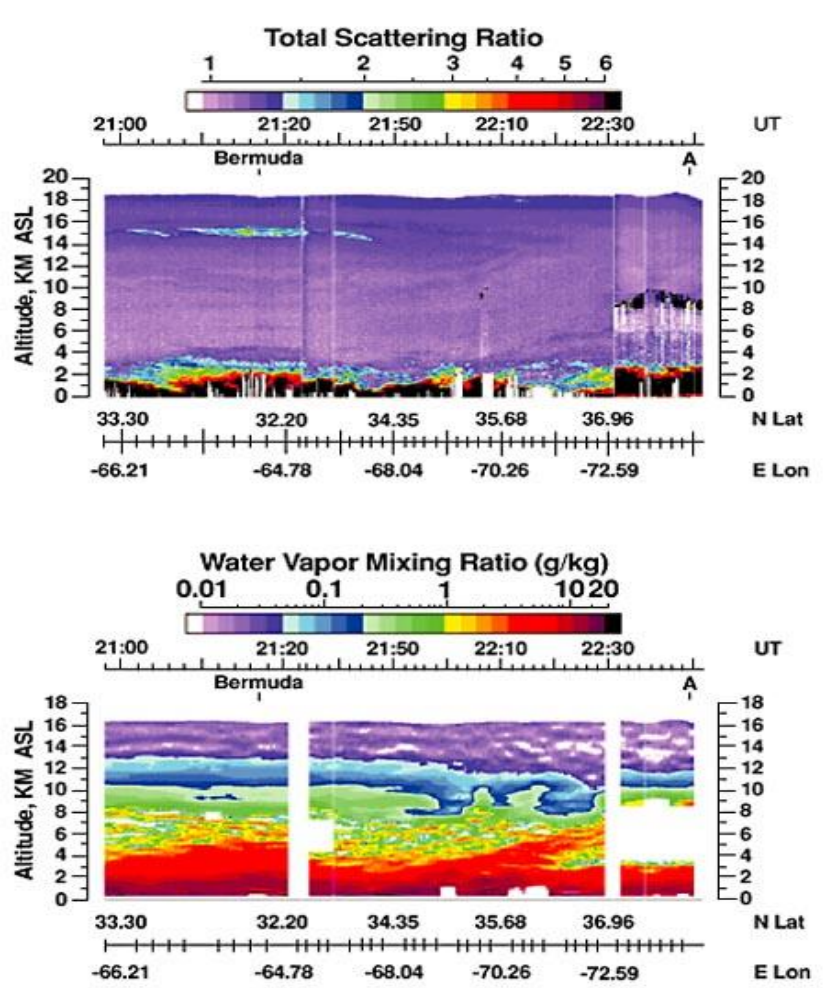

Figure 3: Simultaneous measurements of aerosols (top panel) and water vapor by LASE on-board the Earth Resources 2 aircraft that flew from near Bermuda to Wallops, VA during the TARFOX (Tropospheric Aerosol Radiative Forcing Observational Experiment).

\section{Water Vapor Measurement}

Water vapor is an essential link in the water (hydrologic) cycle, which includes all forms of water (gas, liquid, ice, and snow). Also, water vapor is the main ingredient in cloud formation (which impacts precipitation) and in severe storm development. It is an invisible gas and acts as a buffer for the rise and fall of temperatures in the atmosphere. Once the temperature drops to the dew point, water vapor condenses, releasing heat and the temperature rises again. Conversely, as temperature rises, water evaporates, taking up heat and cooling the atmosphere. Water vapor, a greenhouse gas, also influences the Earth's radiation budget by absorbing outgoing long wave energy.

\subsection{Cloud and Aerosol Measurements}

Simultaneous measurements of clouds and aerosols enhance water vapor investigations conducted using LASE, which can provide additional important information on atmospheric structure and movement. Scientists can also infer meteorological variables from these data, such as the depth of the mixed layer -- the layer closest to the surface where most of the pollution is trapped and where many clouds form. Measurement of the distribution of clouds is important because clouds play a major role in meteorology, rainfall, and the atmospheric radiation balance. 


\section{International Journal of Science and Research (IJSR) \\ ISSN (Online): 2319-7064}

Index Copernicus Value (2015): 78.96 | Impact Factor (2015): 6.391

\subsection{The Instrument}

The LASE transmitter consists of a Ti:sapphire laser pumped by a double pulsed Nd:YAG laser. The frequency of the Ti:sapphire laser is controlled by injection seeding using a diode laser that is frequency locked to a water vapor line in the 815-nm region. The "on" and "off" wavelengths are separated by less than $70 \mathrm{pm}$.

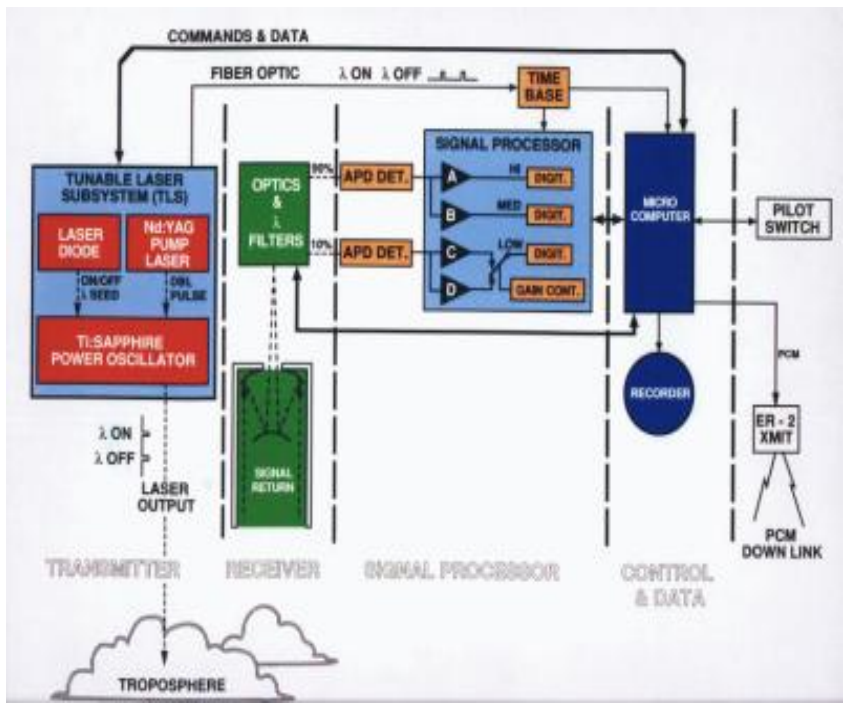

Figure 4: LASE system Block diagram

The laser pulses are sequentially transmitted with about 400 microseconds separation. This permits the use of the same avalanche photodiodes (APD) for detecting the lidar returns. The use of low and high light level APD's provides linear response to atmospheric and cloud/ground returns, respectively. Lidar returns at $5 \mathrm{~Hz}$ are digitized and recorded, and when possible, the data are telemetered to the LASE ground station for real-time processing and experiment control. Operation with strong and weak absorption regions of a preselected water vapor line can be made during the mission to optimize the measurement of water vapor in different altitude regions.

\section{Conclusion}

The LASE Instrument has successfully completed extensive characterization in the lab and validation testing in the field. LASE is self calibrating and does not need external reference data to obtain accurate water vapor measurements. The LASE system has proven to be a reliable, accurate, and sensitive water vapor profiler with the ability to measure water vapor mixing ratios over a large dynamic range $(0.01 \mathrm{~g} / \mathrm{kg}$ to 20 $\mathrm{g} / \mathrm{kg}$ ). Aerosol backscatter ratios can be measured from ground to $20 \mathrm{~km}$ with a vertical resolution of $30 \mathrm{~m}$ and a horizontal resolution of $40 \mathrm{~m}$.

\section{Future Scope}

LASE will be used as a testbed to demonstrate advanced airborne and spaceborne DIAL technologies. These advancements will include new lasers, detectors and receivers for developing the first generation of spaceborne DIAL instruments.

\section{References}

[1] Browell, E. V., Wilkerson, T. D., McIlrath, T. J.: Water vapor differential absorption lidar development and evaluation. Appl. Opt. 18 (1979) 3474-3483.

[2] Browell, E.: Remote sensing of tropospheric gases and aerosols with an airborne DIAL system. In Optical Laser Remote Sensing, edited by D. K. Killinger and A. Mooradian, Springer-Verlag, New York (1983) 138-147.

[3] Ismail, S., Browell, E. V.: Airborne and space borne lidar measurements of water vapor profiles: A sensitivity analysis. Appl. Opt. 28 (1989) 3603-3615.4. Browell, E. V.: LASE Validation Experiment. In 18th ILRC Proceedings, Springer Verlag (1996) this book.

[4] https://www.science.larc.nasa.gov/lidar/

[5] https://www.airbornescience.nasa.gov/instrument/LASE

[6] https://www.nasa.gov/centers/langley/factsheets/LASE

\section{Author Profile}

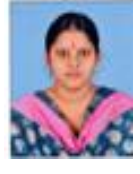

A. Padma Priya presently holds the position of Assistant Professor in the department of Electronics and Communication Engineering at CMR Institute of Technology, Hyderabad. I obtained B.Tech degree in the stream of Electronics and Communication Engineering from D.M.S S.V.H College of Engineering, Machilipatnam in 2008, M.Tech degree in the stream of VLSI \& E.S from Sasi Institute of Engineering \&Technology, Tadepalligudem in 2011. I published various papers in International Journals, International Conferences and National Conferences. My current research interests are Wafer Defect Inspection, Standard cells and Low power VLSI.

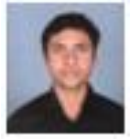

G. Madhu presently holds the position of Assistant Professor in the department of Electronics and Communication Engineering at CMR Institute of Technology, Hyderabad. I obtained B.Tech degree in the stream of Electronics and Communication Engineering from Christu Jyoti Institute of Technology \& Science,Jangaon in 2009, M.Tech degree in the stream of Digital Systems \& Computer Electronics from Guru Nanak Engineering College, Ibrahimpatnam in 2011. I published various papers in International Conferences and National Conferences. My current research interests are VLSI System Design. 